\title{
LA ALQUIMIA ÁRABE: ¿TRANSFORMACIÓN DE LA NATURALEZA O TRANSFORMACIÓN DEL HOMBRE?
}

Rafael Ramón Guerrero*

SINTESIS - La edición de textos alquímicos árabes deja entrever que la tradicional concepción de la alquimia como una ciencia mágica más está condenada. La alquimia, integrada por los estudiosos árabes en el conjunto de saberes que constituyen las ciencias, representa una manifestación de la.necesidad que siente el hombre de verse implicado en su propia transformación. Forma parte, así, de la propia dinámica que el hombre ha vivido a lo largo de su historia. La alquimia ha formulado principios universales a partir de los cuales el hombre se ha lanzado a la buisqueda de su propia realidad, en el deseo de alcanzar su eterna beatitud.

PALABRAS-CLAVE - Filosofia árabe. Alquimia. Ciencias. Teorias cientificas.
ABSTRACT - The edition of Arab alchemistic texts allows to see that the traditional conception of the alchemy like a another magic science is condemned. Alchemy, integrated by the Arab specialists in the group of knowledgements that constitute the sciences, represents a manifestation of the necessity that man feels of seeing itself involved in its own transformation. It is part, this way, of the own dynamics that the man has lived along his history. The alchemy has formulated universal principles starting from which the man has nushed to the search of his own reality, in the desire of reaching his eternal beatitude.

KEY WORDS - Arabic Philosophy. Alchemy. Sciences. Scientifical theories.

\section{Resumen}

Se ha señalado ${ }^{1}$ que la alquimia fue el único saber de tipo práctico relevante entre los medievales que no permaneció entre los saberes que constituyeron la civilización del Occidente moderno, repleta de ciencias prácticas que se perfeccionaron a partir de las antiguas artes mecánicas. Y no perduró, contrariamente a éstas, porque no estaba construida sobre el modelo mecánico, sino sobre el orgánico y erótico, ${ }^{2}$ esto es, como un discurso alegónico y místico que supera a la propia naturaleza, porque se configura como auténtico proceso de creación y no de imitación.

* Universidad Complutense. Madrid (España).

1 C. Gagnon: "Alchimie, techniques et technologie", Cahiers d'études médiévales, VII. Les arts mécaniques au moyen âge, préparé par G. H. Allard et S. Lusignan Montréal - Paris, 1982, p. 131.

2 Ibídem, p. 145.

ก. 3 
Así, al margen del carácter práctico y tecnológico que pudo tener la alquimia medieval, como un saber que estudiaba las características y promovía los cambios de la materia, este arte tuvo un sentido profundo y ajeno al ámbito de lo material, que poco tuvo que ver con el aspecto esotérico, mágico, fantasioso y aun milagroso que durante mucho tiempo se le asoció y que en muy diversos medios se le atribuyó.

Parece que la alquimia pudo nacer en Egipto, en esa vinculación que la propia antigüedad creó entre Hermes Trimegisto y el dios egipcio Thoth, inventor, según el mito platónico, del arte de la escritura y, como consecuencia de ello, del arte de la comunicación. La época helenística, en que las diversas ciencias ocultas quedaron vinculadas entre sí, vio cómo floreció y se desarrolló el estudio de este arte, comenzando a manifestarse la distinción entre dos tipos de hombres de ciencia. Los dos se ocuparon de la naturaleza como compuesta de minerales, vegetales y animales, pero tanto el método como el fin que ambos se proponían fueron completamente diferentes. Mientras que el método y el fin de un tipo de hombre de ciencia, el que se podría llamar "cientifico" propiamente dicho, es el de construir un saber puramente teórico, que no apunta a su utilización práctica, el método y el fin del otro tipo, el que se entrega a las ciencias ocultas, están encaminados a su realización práctica: si se estudian las propiedades de minerales y vegetales es con el fin extraer remedios de ellos, sea como transmutación de unos metales en otros, sea como propiedades terapéuticas de las plantas. ${ }^{3}$

Fue, sin embargo, el mundo árabe el que elaboró un amplio elenco de obras, que elevaron la alquimia al rango de un saber ampliamente difundido y conocido, convirtiéndose en una arraigada tradición que influyó luego en el mundo europeo de la Edad Media y del Renacimiento. Ese saber fue entendido como un conocimiento que se obtenía a través de un largo adiestramiento, precisamente porque incluía un conjunto de doctrinas metafisicas, cosmológicas y cientíicas, así como algunas ideas éticas, al señalar algunos textos que la tarea primordial del adepto ha de ser liberarse de todo aquello que le impida reconocerse como hombre verdadero, que aspira a la inmortalidad. ${ }^{4}$ Trabajando con concepciones e hipótesis que en su época no eran consideradas como disparatadas, llegaron a muchas experiencias interesantes y a descubrimientos notables: moviéndose hacia un mundo que era imaginario, se llegaron a encontrar muchas cosas situadas en ese camino.

Diversos autores árabes que describieron la tipología de las ciencias, incluyeron la alquimia entre las distintas clases de ciencias, entre aquellas de carácter no islámico. Al-Juwârizmî, en su Mafâtĥh al-'ulûm ("Las claves de las ciencias"), la registra en el segundo libro, dedicado a las ciencias extranjeras ('ulûm 'a yam): la alquimia está incluida entre las ciencias teóricas, como una de las ciencias físicas. ${ }^{5}$

3 Una amplia y clara exposición de esta distinción en A.-J. Festugière: La révélation d'Hermès Thismégiste. I. L'Astrologie et les sciences occultes, París, Les Belles Lettres, 1950, p. 187-196.

4

Cf. A. Abel: "De l'alchimie arabe à l'alchimie occidentale", Convegno Intemazionale Oriente e Occidente nel medievo: Filosofia e Scienze, Roma, Accademia Nazionale dei Lincei, 1971, p. 252253.

5 Cf. L. Gardet - M. M. Anawati: Introduction à la théologie musulmane, París, J. Vrin, $2^{\mathbf{a}}$ ed., 1970, p. 111. 
La famosa Enciclopedia de los Ijwân al-Safâ', conjunto de autores del siglo X, vinculados a los ismaelies, establece igualmente una clasificación de las ciencias en la que la alquimia ocupa su lugar entre las ciencias propedéuticas, aquellas que tienen como fin asegurar la subsistencia y aportar cierta comodidad a los hombres. Una parte de la Epístola Séptima, consagrada a Las artes teónicas y su fin, está dedicada a las clases de las ciencias (Fasl fí aŷnâs al-'ulûm) y allí podemos leer lo siguiente:

"Sabe, hermano, que las ciencias a las que se dedican los hombres son de tres géneros: las propedéuticas (al-riyâdiyya), las propias de la Ley religiosa positiva (al-šar 'iyya al-wad 'iyya) y las filosóficas verdaderas (al-falsafiyya al-haqiqiyya). Las propedéuticas, que constituyen la ciencia de las bellas letras ('ilm al-adâb), son las que se han establecido principalmente para procurar el modo de vida y mejorar la vida en este mundo; son nueve clases: la escritura y la lectura; la lengua y la gramática; la aritmética y las transacciones comerciales; la poesía y la prosodia; la adivinación, el augurio y otras semejantes; la magia, los conjuros, la alquimia, la mecánica y otras semejantes; los trabajos artesanales y los oficios; la compra y venta, el comercio, la agricultura y la reproducción de animales; $y$, en fin, la biografia y la historia." ${ }^{6}$

El Catálogo (Fihnist) de Ion al-Nadîm, un librero del siglo X, sitúa la alquimia en una sección completa, la décima, mientras que la séptima la ha consagrado a la filosofía y ciencias antiguas; la octava a las "tertulias nocturnas" (asmâr) y la novena a las creencias ajenas al Islam.

Ibn Jaldûn, el celebrado estudioso de la historia del siglo XIV, también la recoge en su clasificación de las ciencias y le reserva un capítulo completo en su Muqaddima o Introducción a la historia, en la que establece una auténtica sociología del conocimiento. Comienza su capítulo señalando qué es la alquimia:

"La Alquimia. Es la ciencia que estudia la materia (mâdda) por la que se completa, de manera artificial (bi-l-sinâ 'a), la generación đel oro y la plata; expone, además, la operación que conduce a ello. [Los alquimistas] escudriñan todas las cosas formadas (almukawwanât) después de conocer sus mezclas y sus virtudes, esperando descubrir casualmente la materia predispuesta para ello, de tal manera que [escudriñan] además de los minerales los restos de los animales, como los huesos, plumas, huevos y excrementos. Expone luego las operaciones por las que aquella materia pasa de la potencia al acto, como, por ejemplo, la disolución de los cuerpos en sus partes naturales por sublimación, la destilación, la solidificación de los solubles por calcinación, la pulverización de los sólidos en el mortero y en la machacadera y otras semejantes. Es opinión de ellos que por medio de todas estas técnicas se extrae un cuerpo natural que se llama "elixir" (al-iksîr), y que desde él se consigue que un cuerpo mineral, como, por ejemplo, el plomo, el estaño o el cobre, dispuesto para recibir la forma del oro o de la plata por la preparación cercana a la operación, después de haberlo calentado al fuego, se vuelva oro acendrado. Como hablan de manera enigmática con su terminologia, a este elixir le dan el nombre de "espíritu" (al-rûh), y a la substancia corpórea (ŷism) en la que se encuentra la llaman "cuerpo" (yasad). Expone también esta terminologia y la forma en que esta operación técnica realiza la transmutación de estos cuerpos dispuestos para la forma del oro y de la plata. Es la ciencia de la alquimia ('ilm al-kîmiyyâ)."7

Rasâ'il ljwân al-Safâ', Beirut, Dâr al-Sâdir, 1957, I, p. 266-267.

Ibn Jaldûn: Muqaddima, ed. A. A. Wafi, El Cairo, vol. IV, 1962, p. 1186-1187. Hay trad. española, México, FCE, 1977, p. 947. 
Reconoce Ibn Jaldûn, después de transcribir una misiva de un personaje apenas conocido, Ibn Bišrûn, que los alquimistas se sirven de un lenguaje enigmático, difícil de explicar y de comprender, lo que muestra que la alquimia, dice, no es un arte natural, sino uno de los procedimientos por los que los espíritus ejercen influencia sobre la naturaleza y actúan sobre ella, debiendo por tanto ocultarse en el lenguaje para que la alquimia no sea reprobada por las leyes religiosas, y no, como se suele entender, para preservar el secreto de ella. Ion Jaldûn desautoriza la alquimia en sus dos aspectos, el puramente físico de la transmutación de los metales en oro, y el más espiritual de ejercer influencia sobre la naturaleza. Lo apunta también al comienzo de su discurso, cuando dice que se han atribuido a Algazel libros sobre alquimia, cosa inverosimil porque, tratándose de un espíritu superior, no podria haber estudiado y mucho menos haber hecho suyos los errores de los alquimistas. ${ }^{8}$ Más adelante, incluso, dedica un capítulo a la refutación de la alquimia, en el que señala que los hombres, arrastrados por la codicia, se dedican al estudio de la alquimia en la creencia de que así podrán enriquecerse de una manera rápida y simple. ${ }^{9}$

Hubo importantes nombres de la cultura musulmana, especialmente entre los filósofos, que entendieron que la alquimia era poco menos que un fraude intelectual. Así lo dice Abû l-Hasan al- 'Âmirî, ${ }^{10}$ un jurasaní perteneciente a la tradición neoplatónica en el Islam que murió en Nišapur en el año 992. En su Información sobre los méritos del Islam, ${ }^{11}$ donde trata de mostrar la superioridad del Islam sobre las demás religiones basándose en una argumentación racional y sin obcecarse con la tradición, señala la existencia de ciencias religiosas y ciencias filosóficas, pero también otras que son desaprobadas por los filósofos y que no deben ser enseñadas a la gente, porque su aplicación es perjudicial para ellos; son las ciencias de la magia, los conjuros, los amuletos y la alquimia. ${ }^{12}$

Ibn Jaldûn nos dice que al-Fârâbî pretendía que la transmutación de los metales era algo realizable, porque se pueden cambiar sus accidentes y tratarlos de manera artificial. ${ }^{13}$ Por el contrario, Avicena destacó por sus críticas a la alquimia, llevado quizá por su espiritu empírico, acostumbrado como estaba a las ciencias positivas y a la costumbre de la experimentación, precisamente porque esa ciencia no descansaba en ningún principio empírico. Puso de relieve los errores de la alquimia y aportó numerosos argumentos en los que se apoyaron quienes se oponían a ella ${ }^{14} \mathrm{Y}$ aunque escribió un tratadito en el que parece describir las operaciones alquímicas, la Epístola sobre el elixir, ${ }^{15}$ sin embargo, su comienzo no deja lugar a dudas sobre su postura:

\footnotetext{
Ibídem, p. 1188; trad. p. 948.

Ibídem, pp. 1215-1224; trad. pp. 975-986.

${ }^{10}$ Sobre este autor, cf. E. K. Rowson: A Muslim Philosopher on the Soul and its Fate. Al-'Âmin's "Kitâb al-Amad 'alâ l-abad", New Haven, Connecticut, American Oriental Society, 1988.

Al-I lâm bi-manâqib al-Islâm, Al-Riyâd, Dâr al-Asala, 1988.

Cf. F. Rosenthal: The Classical Heritage in Islam, Londres, Routledge, 1975, p. 63.

Obra citada, p. 1219; trad. p. 978.

14 Un análisis completo de la posición de Avicena sobre la alquimia puede verse en G. C. Anawati: "Avicenne et l'alchimie", Convegno Intemazionale Oriente e Occidente nel medievo: Filosofia e Scienze, Roma, Accademia Nazionale dei Lincei, 1971, p. 285-341.

Risâlat al-Iksîr, ed. A. Ateš, Turkiyat Mecmuasi, 1952, p. 27-54. G. A. Anawati reproduce esta edición, ofrece una traducción francesa y edita también la versión latina, art. cit., p. 302-339.
}

15 
“Yo había estudiado meticulosamente las cuestiones naturales. Las opiniones que sostenían los partidarios de la alquimia eran uno de estos asuntos. Quienes son más excelentes y poseen más ciencia contradicen a aquéllos y declaran que sus opiniones son falsas. En mi oficio no me queda más remedio que conocer la doctrina de los dos grupos. He considerado la mayoría de los libros de quienes apelan al arte [de la alquimia] y los he encontrado carentes de la argumentación silogística (al-qiyâs) que es el sustento de todo arte, y he hallado que la mayor parte de lo que hay en ellos es semejante a puros dislates. He considerado [lo que dicen] sus contradictores y he encontrado una refutación débil y una argumentación silogística mediocre. Con [argumentación] semejante a ésta no se refuta un arte. ${ }^{16}$

El mundo árabe había desarrollado un saber en el que se mezclaban experiencias reales y verificables - y en este sentido tuvo aplicaciones en medicina, en farmacia y en otras técnicas, como las de la escritura y la tintura - con afirmaciones que carecían de fundamento. Junto a datos que podian ser confiados a la mayoría, había otros que debían ser conservados en secreto. No dejan de hacer experiencias, dice Ibn Jaldûn, ${ }^{17}$ y se transmiten las reglas y principios adquiridos en los libros de los antiguos maestros del arte, discutiendo entre sí sobre el sentido y la manera de interpretar los enigmas y secretos que tales libros contienen.

Las premisas primeras de esta ciencia descansaban en que todos los metales son, en realidad, el mismo, por lo que es posible la transmutación de uno en otro; en que el oro es el más puro de todos ellos; y en que hay una substancia capaz de transformarse continuamente en metales puros. Estas premisas, a su vez, tenían como fundamento la idea de que los metales eran considerados como seres vivos, susceptibles, por tanto, de desarrollarse y evolucionar en estados más o menos perfectos, siendo el "elixir" el espíritu que permite esa transformación. La utilización de las doctrinas filosóficas dominantes en la época, en especial la del emanacionismo en el que el intelecto humano ocupa su lugar en una jerarquía de inteligencias superiores y en el que éstas realizan tales operaciones que de ellas procede la aparición de las formas y de la naturaleza, permitía dar sentido a esa transformación, sobre todo, porque todo procede del Uno y todo vuelve al Uno.

Afirmar la actividad de las causas segundas que del emanacionismo se deducía implicaba encerrar al universo en unas leyes deterministas y rechazar la providencia divina y la libertad humana. Se eliminaba este determinismo apelando a la providencia divina, que había previsto las influencias astrales sobre el hombre. La astrologia, como ciencia que aprehende las relaciones entre cielo y tierra, no sólo es contemplación de la armonía del universo, sino también saber práctico que permite al hombre intervenir en los fenómenos. Y la alquimia, igualmente, facilita el conocimiento de los secretos y propiedades ocultas de la naturaleza y hacen posible su manipulación y transformación. Y, aunque se pensara en la influencia que sobre el hombre ejercían las fuerzas mágicas de la naturaleza, más allá de las pretensiones de magos y alquimistas, había en ellos un deseo de conocer la naturaleza, dominándola, que contribuyó a la consideración del hombre como imagen de Dios, pues, cómo éste, también conoce y puede.

${ }_{16}$ Texto en G. A. Anawati: art. cit., p. 302.

17 O. c., p. 1216; trad. p. 976. 
Porque no hay que perder de vista que las obras alquímicas en el mundo árabe se teñian con una apariencia de saber filosófico, en el que estaba implícita una concepción del hombre y de sus relaciones con las cosas. Se creía, como acabo de decir, en la influencia de los cuerpos celestes en el mundo sublunar y en los hombres. Esto fue afirmado por los mismos filósofos, como hizo al-Fârâbî, ${ }^{18}$ quien sostuvo lo siguiente:

"No es más que por medio de un calor más o menos grande como los cuerpos actúan sobre aquellos que le son inferiores. Las cantidades de este calor provocan en estos cuerpos otros efectos y formas. De éstas provienen otros accidentes. ${ }^{19}$

Por ello, no es extraño encontrar cómo autores de obras alquímicas se sirven de fragmentos de filósofos para asentar teóricamente su saber. Un caso conocido es el uso que hizo el célebre Picatrix, texto muy leído en la Edad Media latina y muy influyente en autores medievales y renacentistas. El tratado árabe lleva por título Gâyat al-hakîm o El fin del sabio y fue compuesto en la España musulmana entre el siglo $\mathrm{X}$ y el siguiente. Esta obra comienza con un largo texto tomado literalmente de los Fusûl muntaza ‘a de al-Fârâbî acerca de la sabiduría, ${ }^{20}$ cuya búsqueda es un deber para el hombre, porque ilumina al intelecto y al alma con la luz bella y eterna. Y más adelante son textos referentes al hombre los que el autor de la Gâyat al-hakîm copia de al-Fârâbî, especialmente aquellos que hablan de la perfección del hombre y de su felicidad. Más tarde, el alquimista Nicolás Flamel (†1417) indicó que la Obra hace bueno al hombre porque arranca de él la raíz del pecado, convirtiéndolo en generoso, manso, piadosos, creyente y temeroso de Dios. ${ }^{21}$

Porque es éste el otro objetivo al parecer buscado en la alquimia. Ésta, en un segundo momento, deja de ser ya un mero arte de transformación de la naturaleza para convertirse en una búsqueda de la transmutación del hombre. Conocer la naturaleza y poder transformarla quiere decir conocerse a sí mismo y poder transformarse. Es la concepción neoplatónica del hombre como microcosmos lo que está en juego. Conocer es convertirse en lo que se conoce; el hombre extrae de sí todo aquello que puede conocer y lo muda en su objeto, transformándose a su vez. La alquimia va de la mutación material a la mutación espiritual, elevando al hombre a su origen divino, al Uno del que procede. Es lo que se desprende de los textos del Corpus atribuido a Ŷâbir b. Hayyân, ${ }^{22}$ en donde se presenta el fin supremo del alquimista como el de llevar a cabo el retorno a la fuente primera.

${ }^{18}$ Cf. Th.-A. Druart: "Astronomie et astrologie selon Farabi", Bulletin de Philosophie Médiévale, 20 (1978) 43-47.

19 Maqâla fi l-ỵihat allatî yasihhu 'alay-hâ al-qawl fỉ ahkâm al-nuỵ̂m ("Tratado sobre la manera en que es verdad aquello que se dice en las afimaciones astronómicas"), ed. M. Mahdi, en U. Amîn (ed.): Nusûs falsafiyya, El Cairo, 1976, p. 69; trad. francesa: Th.-A. Druart: "Le second traité de Farabi sur la validité des affirmations basées sur la position des étoiles", 'Bulletin de Philosophie Médiévale, 21 (1979) 47-51.

Cf. R. Ramón Guerrero: "Textos de al-Fârâbî en una obra andalusí del siglo XI: Gâyat al-hakîm de Abû Maslama al-Maŷnitî", Al-Oantara, 12 (1991) 3-17. París, Les Belles Lettres, 1986. 
Es esta nueva visión de la alquimia, la que afecta al hombre y deja a un lado la doctrina de la práctica operativa de la alquimia, la que ha sido considerada por A. Abel como de un alcance ético y político de primer grado ${ }^{23}$ presente tanto en los textos de Ŷâbir como en los de los Ijwân al-Safâ', entendiendo ese alcance como aquella perfección que hay que alcanzar, cuya recompensa, felicidad supre$\mathrm{ma}$, es el acceso a las inteligencias superiores y a la fuente originaria. Fueron ellos los que afirmaron con nitidez la semejanza del hombre con la naturaleza, con el macrocosmos, haciendo de él un microcosmos:

"En esta Epistola queremos recordar el significado que tiene la expresión de los sabios de que el hombre es un universo pequeño ('âlam sagîr). Decimos: Sabe que los primeros sabios, cuando conșideraron este universo corpóreo con las miradas de sus ojos, presenciaron sus cosas aparentes (zawâhir) con sus sentidos, reflexionaron sobre sus estados con sus intelectos, consideraron las clases de todos sus individuos con su perspicacia y reconocieron las clases de sus particulares con su visión, no encontraron que hubiese ninguna de la totalidad de sus partes más perfecta en cuanto a su constitución y más completa en cuanto a su forma ni, en suma, más intensa en cuanto a su semejanza que el hombre. Esto es así porque el hombre es un conjunto de cuerpo físico (ŷasad yusmânî) y alma espiritual (nafs rûhâniyya). Encontraron en la disposición de la constitución de su cuerpo imágenes de todos los seres que hay en el universo corpóreo respecto a la maravillosa composición de sus esferas, a las divisiones de sus signos del Zodíaco, a los movimientos de sus astros, a la composición de sus elementos constitutivos y sus principios, a la diversidad de sus substancias minerales, las clases de sus especies vegetales y las singularidades de sus estructuras animales. Encontraron también que las especies de las creaturas espirituales pertenecientes a los ángeles, a los genios, al hombre y a los demonios, las almas de los restantes animales y las clases de sus estados en el mundo, eran semejantes al alma humana y a las manifestaciones de sus fuerzas en la constitución del cuerpo. Cuando estas cosas referentes a las formas del hombre les resultaron evidentes, lo llamaron por esta razón microcosmos ('âlam sagîr)." ${ }^{24}$

La alquimia, en este sentido más profundo que apunta a la transmutación del hombre por reflejar en sí la estructura del universo, se propone desvelar el funcionamiento oculto de éste, conocer sus leyes y poner de relieve el dinamismo de la vida del hombre, pero ofreciendo una representación gnóstica del mundo, en la que las categorias lógicas no tienen lugar ${ }^{25}$ Ŷabir b. Hayyân pretendió ofrecer una visión superior de la alquimia como un saber divino que representa la cima de la sabiduría: "Este Arte es calificado de 'Sabiduría' por excelencia, porque constituye el límite extremo del saber filosófico, siendo él mismo ilimitado" ${ }^{26} \mathrm{Es}$, en definitiva, el Arte que trata de poner de manifiesto lo oculto y de ocultar lo manifiesto.

Así, se ha pensado recientemente,$^{27}$ que la alquimia, lejos de ser un mero procedimiento de metalurgia, pretendía más, en la obra de sus más conspicuos representantes, una verdadera transformación del hombre, cuyo alcance iba más allá de

\footnotetext{
A. Abel: Art. cit., p. 266.

Rasâil Ijwân al-Safâ', vol. II, p.456-457.

Cf. P. Lory: Alchimie et mystique en terre d'Islam, París, Ed. Verdier, 1989, p. 45.

Kitâb al-lâhût, trad. franc. P. Lory: Dix traités d'alchimie, Paris, Ed. Sindbad, 1983, p. 100.

Lo pone de relieve P. Lory: Dix Traités, Introduction, p. 12-13.
} 
las ventajas materiales que la metalurgia podía proporcionar. Incluso se ha llegado a distinguir tres categorías en la alquimia árabe: la espiritual y simbólica, que se propone la transformación del alma; la puramente material o física, que busca la mutación de los metales; y, en fin, aquella que se propone la transformación del alma a partir de las operaciones puramente externas. ${ }^{28}$ Alternativas excluyentes 0 complementarias que, en cualquier caso, apelan a un mejor conocimiento de la obra alquímica para tratar de precisar el sentido que el Arte tuvo en el contexto histórico, filosófico y científico en que nació y se desarrolló.

${ }^{28}$ S. H. Nasr: Sciences et savoir en islam, Paris, Ed. Sindbad, 1979, p. 266. 